BMJ Open Sport \& Exercise Medicine

\title{
Game on: a cycling exergame can elicit moderate-to-vigorous intensity. A pilot study
}

\author{
Jonathan Berg (D) ,,2 Trine Moholdt (D) 1,2
}

To cite: Berg J, Moholdt T. Game on: a cycling exergame can elicit moderate-to-vigorous intensity. A pilot study. BMJ Open Sport \& Exercise Medicine 2020;6:e000744. doi:10.1136/ bmjsem-2020-000744

Accepted 10 March 2020

\section{ABSTRACT}

Objectives The aims of this pilot study were to investigate oxygen uptake $\left(\mathrm{V}_{2}\right)$ while playing a cycling exergame to assess exercise intensity to determine its potential as a feasible exercise alternative to improve aerobic fitness, and to assess the validity of using heart rate $(\mathrm{HR})$ to estimate $\dot{\mathrm{V}} \mathrm{O}_{2}$ in exergaming.

Methods Five males (age: $32 \pm 8$; peak oxygen uptake $\left.\left(\dot{\mathrm{V}} \mathrm{2}_{2 \text { peak }}\right): 47.9 \pm 7.8 \mathrm{~mL} \cdot \mathrm{kg}^{-1} \cdot \mathrm{min}^{-1}\right)$ and five females (age: $27 \pm 3 ; \mathrm{VO}_{2 \text { peak }}: 33.9 \pm 4.6 \mathrm{~mL} \cdot \mathrm{kg}^{-1} \cdot \mathrm{min}^{-1}$ ) played the cycling exergame 'Pedal Tanks' for $45 \mathrm{~min}$, with measurements of $\mathrm{HR}$ and $\dot{\mathrm{V}} \mathrm{O}_{2}$.

Results Average and peak $\dot{\mathrm{V}} \mathrm{O}_{2}$ during exergaming were $61.7 \pm 10.1 \%$ and $78.3 \pm 11.7 \%$ of $\dot{\mathrm{V}} 0_{2 \text { peak }}$, respectively, whereas average and peak HR were $80.0 \pm 9.4 \%$ and $91.5 \% \pm 6.7 \%$ of $H R_{\text {peak }}$. There was a strong positive correlation between $\mathrm{VO}_{2}$ and $\mathrm{HR}$ for all participants $(p<0.05)$ although estimated $\dot{\mathrm{V}} \mathrm{O}_{2}$ from $\mathrm{HR}$ was $9 \%$ higher than that measured during exergaming.

Conclusion Our preliminary data suggest that the cycling exergame we investigated can elicit moderateto-vigorous intensities and may therefore be a viable alternative to conventional aerobic exercise. The exercise intensity during exergaming was overestimated when using HR alone.

\section{INTRODUCTION}

There is abundant evidence for the health benefits of regular physical activity ${ }^{2}$ and cardiorespiratory fitness is a strong predictor of health and longevity. ${ }^{3}$ Still, only one out of three Norwegian adults fulfil current guidelines for physical activity for health benefits (>150min of moderate intensity/week or $75 \mathrm{~min}$ of vigorous intensity/week). ${ }^{4}$ Two of the most frequently reported reasons for not being sufficiently physically active are a lack of time and a lack of enjoyment/motivation. ${ }^{6}$ Cardiorespiratory fitness is more strongly associated with health than physical activity ${ }^{3}$; therefore interventions aiming to improve health outcomes should focus on improving maximum oxygen uptake $\left(\dot{\mathrm{V}} \mathrm{2}_{2 \max }\right)$. Vigorous intensity exercise, such as high-intensity interval training (HIIT), has been found to be more effective in improving

\section{What are the new findings}

- Oxygen uptake whilst playing a biking exergame can be classified as moderate to vigorous.

- Exercise intensity during exergaming was unaffected by aerobic fitness.

- Relying solely on heart rate will overestimate exercise intensity in exergaming.

- The cycling exergame we tested can be a viable alternative to traditional endurance exercise. health and $\dot{\mathrm{VO}}_{2 \text { max }}$ than both low/moderate-
intensity exercise.

Exergaming, which is the play of videogames that require physical exertion, is an enjoyable alternative to traditional exercise. ${ }^{1011}$ To our knowledge, there is no data on the prevalence of exergaming, but about one third of the Norwegian population play some form of digital game each day. ${ }^{12}$ Since we know that children and adolescents who play exergames are more likely to also play regular videogames, ${ }^{13}$ there should be a great potential for introducing exergames also in the adult population. However, many commercially available exergames simulate traditional exercise which may not be motivating for people who do not already enjoy exercise. ${ }^{14}$ In addition, studies on different exergames indicate that they at most elicit moderate exercise intensities, ${ }^{11}$ 15-17 which can limit their potential as a viable alternative to improve cardiorespiratory fitness. Furthermore, many of the studies investigating exercise intensity during exergaming have been limited by only using heart rate (HR) as measure of intensity, which can be disproportionately higher than oxygen uptake $\left(\dot{\mathrm{VO}}_{2}\right)$ during exergaming. ${ }^{1718}$ Therefore, we suggest that HR measurements should be supplemented with assessment of $\dot{\mathrm{VO}}_{2}$ to more accurately report exercise intensity in exergaming. Currently, data demonstrating moderate-to-vigorous intensities in exergaming have been limited either by relying on $\mathrm{HR}$ to assess exercise intensity and/or by simulating traditional exercise. ${ }^{18-20}$ 
Table 1 Anthropometric and physiological characteristics of the participants (means \pm SD)

\begin{tabular}{|c|c|c|c|c|c|c|}
\hline Subject & Sex & $\begin{array}{l}\begin{array}{l}\text { Age } \\
\text { (years) }\end{array} \\
\end{array}$ & $\begin{array}{l}\text { Height } \\
\text { (cm) }\end{array}$ & $\begin{array}{l}\text { BMI } \\
\left(\mathrm{kg} / \mathrm{m}^{2}\right)\end{array}$ & $\begin{array}{l}\dot{\mathrm{V}} \mathrm{O}_{\text {2peak }} \\
\left(\mathrm{L} \cdot \mathrm{min}^{-1}\right)\end{array}$ & $\begin{array}{l}\dot{\mathrm{V}} \mathrm{O}_{\text {2peak }} \\
\left(\mathrm{mL}^{-1} \cdot \mathrm{kg}^{-1} \cdot \mathrm{min}^{-1}\right)\end{array}$ \\
\hline 1 & $M$ & 33 & 189 & 23.8 & 4.35 & 51.2 \\
\hline 2 & $\mathrm{~F}$ & 28 & 176 & 34.2 & 3.64 & 34.3 \\
\hline 3 & $\mathrm{~F}$ & 29 & 162 & 24.8 & 2.26 & 34.7 \\
\hline 4 & $\mathrm{~F}$ & 28 & 164 & 23.8 & 2.58 & 40.3 \\
\hline 5 & $\mathrm{M}$ & 22 & 184 & 22.5 & 4.16 & 55.1 \\
\hline 6 & $\mathrm{~F}$ & 25 & 163 & 38.4 & 2.79 & 27.4 \\
\hline 7 & $M$ & 35 & 185 & 22.8 & 4.09 & 52.7 \\
\hline 8 & $\mathrm{~F}$ & 23 & 175 & 25.8 & 2.59 & 33.0 \\
\hline 9 & $M$ & 42 & 169 & 37.1 & 3.82 & 35.9 \\
\hline 10 & $M$ & 28 & 177 & 21.8 & 3.04 & 44.5 \\
\hline Mean \pm SD & & $29 \pm 6$ & $174 \pm 10$ & $27.5 \pm 6.4$ & $3.33 \pm 0.77$ & $40.9 \pm 9.5$ \\
\hline
\end{tabular}

$\mathrm{BMI}$, body mass index; $\dot{\mathrm{V}}_{\text {2peak }}$, peak oxygen uptake.

It is important to establish enjoyable, yet effective, ways of exercising for individuals who are not motivated by traditional exercise training.

The aims of this pilot study were therefore to assess exercise intensity, measured as $\dot{\mathrm{V}} \mathrm{O}_{2}$ while playing a cycling exergame, and to investigate associations between peak oxygen uptake $\left(\mathrm{V}_{2} \mathrm{2peak}\right)$ and attained exercise intensity during exergaming. Our hypothesis was that exercise intensity would be classified as vigorous $(>64 \%$ of $\mathrm{VO}_{2 \text { peak }}$ ) in periods during the game and that relative exercise intensity would be negatively correlated with the individuals' $\mathrm{V}_{2 \text { peak }}$. In addition, we hypothesised that HR measurements would overestimate exercise intensity in exergaming.

\section{METHODS}

\section{Participants}

Ten healthy men and women volunteered and took part in this study (characteristics in table 1). Subjects were recruited via word-of-mouth and to be included they had to be 18 years or more and able to ride a bike for

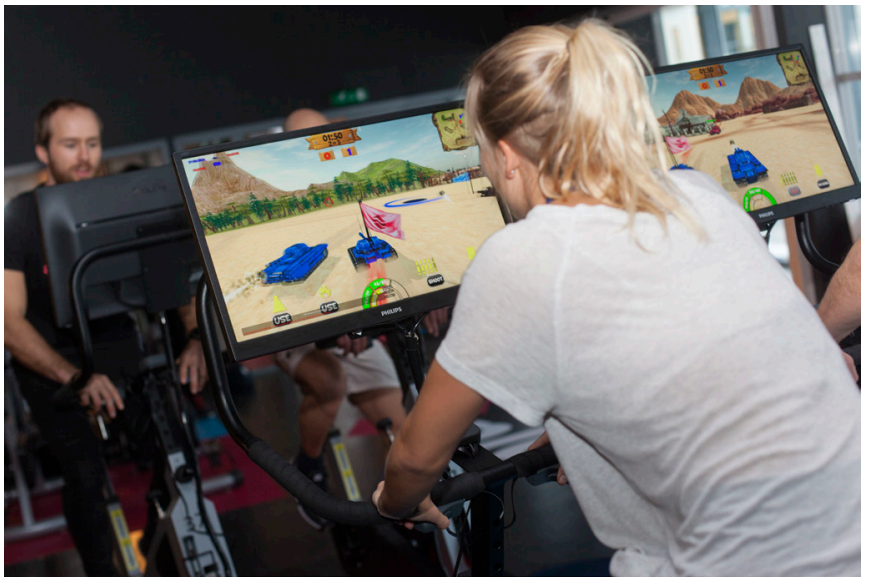

Figure 1 Experimental set-up of exergaming with the cycling exergame. minimum $45 \mathrm{~min}$. All subjects gave written informed consent in accordance with the Declaration of Helsinki. We submitted the study protocol to the Regional Committee for Medical and Health Research Ethics (REK-midt 2017/506) who evaluated that the study would not need an ethical approval from them. Patients and/or the public were not involved in the design, or conduct, or reporting or dissemination plans of this research.

\section{Experimental design}

All participants completed two testing sessions on separate, non-consecutive days, 1 day of baseline testing and 1 day with an exergaming session. The baseline testing consisted of an incremental exercise test to exhaustion on a bicycle ergometer to determine $\dot{\mathrm{V}} \mathrm{O}_{\text {2peak }}$ and an exergaming familiarisation session. On the second day of testing, the participants played the exergame 'PedalTanks' for $45 \mathrm{~min}$.

\section{Pedal Tanks exergame}

Pedal Tanks is a recently developed online multiplayer that capture the flag arena game played on a regular stationary bike. Each player control a tank by using the pedals and six buttons on the handlebar of the bike. The game is played with four players, in teams of two, where the aim of the game is to capture the opponent's flag and bring it back to your own base. Movement in the game is encouraged through the aim, with an increased cycling cadence generating increased velocity of the tank and regeneration of ammunition (figure 1). Each game consists of a preselected number of rounds that end once one team manages to capture the flag and bring it home to their base or when the timer runs out, followed by a short break. ${ }^{21}$

\section{Measurements}

Participants performed an incremental exercise test on an electronically braked cycle ergometer (Lode). The test began with a 10-min warm-up with a self-selected 


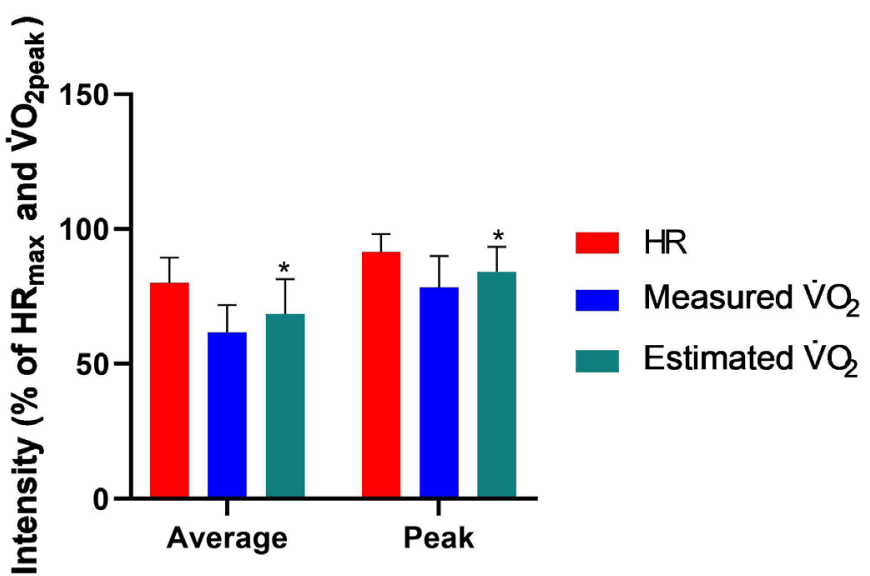

Figure 2 Exercise intensity during exergaming. Heart rate, measured $\dot{\mathrm{VO}}_{2}$ and estimated $\mathrm{V}_{2}$ (using the formula: $\% \dot{\mathrm{VO}}{ }_{2 \text { peak }}=1.369-\left(\% \mathrm{HR}_{\text {peak }}-40.99\right)$. Intensity expressed as a percentage of heart rate peak $\left(\mathrm{HR}_{\text {peak }}\right)$ and peak oxygen uptake $\left(\dot{\mathrm{V}} \mathrm{2}_{2 \text { peak }}\right)$. * $=$ Significantly different from measured $(p<0.05)$.

cadence before we increased work rate by $10-30 \mathrm{~W} \cdot \mathrm{min}^{-1}$, depending on the assumed fitness level of the participant, in order to reach volitional exhaustion in 8-12 min. Criteria for attainment of $\mathrm{VO}_{\text {2peak }}$ were a levelling off in $\mathrm{O}_{2}$-uptake, respiratory exchange ratio $>1.10$ and/or volitional exhaustion. ${ }^{22}$ We reported $\mathrm{V}_{2 \text { peak }}$ as the mean of the three highest $10 \mathrm{~s}$ values during the test and $\mathrm{HR}_{\mathrm{p}}$ as the highest $5 \mathrm{~s}$ HR measurement. Due to technical difficulties we were not able to obtain HR for one participant and for this person we estimated $\mathrm{HR}_{\text {max }}$ using the formula $211-0.64 \times$ age. $^{23}$

Participants wore HR monitors (Polar H10 sensors) during the entire exergaming session. To minimise discomfort for the participants, we only measured $\dot{\mathrm{VO}}_{2}$ during the last $20 \mathrm{~min}$ of exergaming and reported the average and peak $\dot{\mathrm{V}} \mathrm{O}_{2}$ as percentages of $\dot{\mathrm{V}} \mathrm{O}_{2 \text { peak }}$. $\mathrm{HR}$ for the last $20 \mathrm{~min}$ of exergaming is reported as percentage of $\mathrm{HR}_{\text {peak }}$. For both $\mathrm{HR}$ and $\mathrm{VO}_{2}$, exercise intensity was

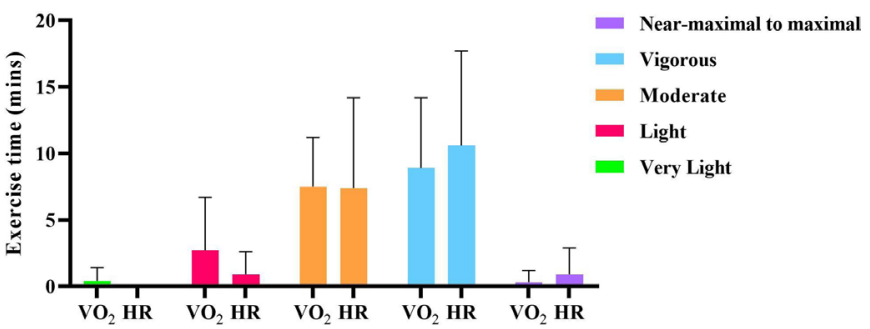

Figure 3 Time in different intensity zones during exergaming. Time in the different intensity zones during the last 20 min of playing the exergame Pedal Tanks. Intensity expressed as a percentage of heart rate peak $\left(\mathrm{HR}_{\text {peak }}\right)$ and peak oxygen uptake $\left(\mathrm{V}^{\mathrm{V}} \mathrm{2}_{2 \text { eak }}\right)$. Intensity zones categorised into very light $\left(<37 \% \dot{\mathrm{VO}} \mathrm{2peak}^{2 \text { peak }} /<57 \% \mathrm{HR}_{\text {peak }}\right)$, light $\left(37 \%-45 \% \dot{V O}_{2 \text { peak }} / 57 \%-63 \% \mathrm{HR}_{\text {peak }}\right)$, moderate $\left(46 \%-63 \%\right.$ Vं $\left.{ }_{2 \text { peak }} / 64 \%-76 \% \mathrm{HR}_{\text {peak }}\right)$ ) 'vigorous' (64\%-90\% $\dot{\mathrm{V}} \mathrm{2pak} / 77 \%-95 \% \mathrm{HR}_{\text {peak }}$ ) and 'Near-maximal to maximal' $\left(\geq 91 \% \mathrm{VO}_{2 \text { peak }} / \geq 96 \% \mathrm{HR}_{\text {peak }}\right)$. Data are displayed as means \pm SD. classified as 'Very light' ( $\left.<37 \% \dot{\mathrm{V}} \mathrm{O}_{2 \text { peak }} /<57 \% \mathrm{HR}_{\text {peak }}\right)$, 'Light (37\%-45\% $\left.\mathrm{VO}_{2 \text { peak }} / 57 \%-63 \% \mathrm{HR}_{\text {peak }}\right)$, Moderate $\left(46 \%-63 \% \dot{\mathrm{VO}}_{2 \text { peak }} / 64 \%-76 \% \mathrm{HR}_{\text {peak }}\right)$, 'Vigorous' (64\%$90 \% \dot{\mathrm{VO}}_{2 \text { peak }} / 77 \%-95 \% \mathrm{HR}_{\text {peak }}$ ) and 'Near-maximal to maximal' $\left(\geq 91 \% \dot{V}^{2 \text { peak }} / \geq 96 \% \mathrm{HR}_{\text {peak }}\right){ }^{24}$

For both the incremental exercise test and the exergaming session, we continuously measured and recorded ventilatory variables with a Metamax portable system (Metamax I; Cortex) or a MetaLyzer 3B system (Cortex) (the same system was used for both test sessions for each participant). We calibrated against ambient air and commercial gas with known concentrations of $\mathrm{O}_{2}$ $(15.00 \%)$ and $\mathrm{CO}_{2}(5.00 \%)$ before each test session. $\mathrm{O}_{2}$ and $\mathrm{CO}_{2}$ concentrations of room air were measured and the flow transducer was calibrated using a $3 \mathrm{~L}$ highprecision calibration syringe.

\section{Statistical analysis}

We did not perform a sample size calculation due to the pilot nature of the study. We calculated mean and SD for all variables. We analysed the association between $\mathrm{HR}$ and $\dot{\mathrm{VO}}_{2}$ during exergaming using linear regression after inspection of homoscedasticity and normality of the residuals. To determine whether using HR overestimated exercise intensity we calculated estimated relative peak and average $\dot{\mathrm{V}}$, from relative $\mathrm{HR}$ for all participants using the formula $\% \dot{\mathrm{V}} \mathrm{O}_{2 \text { peak }}=1.369-\left(\% \mathrm{HR}_{\text {peak }}-40.99\right){ }^{25}$ We compared the estimated and measured values using paired samples t-tests. In addition, we assessed level of agreement between estimated and measured $\mathrm{V}_{2}$ using The Bland-Altman plot. ${ }^{26}$ To investigate the correlation between $\dot{\mathrm{V}}_{2}$ peak and attained exercise intensity during exergaming we used Pearson's product-moment correlation. All analyses were performed using SPSS V.25.0 programme for Windows and GraphPad Prism V.8.0 with level of significance set at $\mathrm{p}<0.05$.

\section{RESULTS}

Average $\dot{\mathrm{V}} \mathrm{O}_{2}$ during exergaming was $25.0 \pm 5.9 \mathrm{~mL} \cdot \mathrm{k}$ $\mathrm{g}^{-1} \cdot \mathrm{min}^{-1}$, corresponding to $61.7 \pm 10.1 \%$ of $\dot{\mathrm{VO}}_{2 \text { peak }}$, whereas peak $\dot{\mathrm{V}} \mathrm{O}_{2}$ during exergaming was $31.7 \pm 7.5 \mathrm{~mL} \cdot \mathrm{k}$ $\mathrm{g}^{-1} \cdot \mathrm{min}^{-1}$, corresponding to $78.3 \pm 11.7 \%$ of $\dot{\mathrm{V}} \mathrm{O}_{2 \text { peak }}$ (figure 2). Average HR attained during exergaming was $145 \pm 20$ beats $\cdot \mathrm{min}^{-1}$, equivalent to $80.0 \pm 9.4 \%$ of $\mathrm{HR}_{\text {peak }}$, whereas maximum $\mathrm{HR}$ during exergaming was $169 \pm 15$ beats $\cdot \mathrm{min}^{-1}$, equivalent to $91.5 \pm 6.7 \%$ of $\mathrm{HR}_{\text {peak }}$ (figure 2). During the $20 \mathrm{~min}$ of data collection during exergaming, $\dot{\mathrm{V}} \mathrm{O}_{2}$ was equivalent to very light intensity for $0.4 \pm 1 \mathrm{~min}$, light intensity for $2.7 \pm 4.0 \mathrm{~min}$, moderate intensity for $7.5 \pm 3.7 \mathrm{~min}$, vigorous intensity for $8.9 \pm 5.3 \mathrm{~min}$ and with near-maximal to maximal intensity for $0.3 \pm 0.9 \mathrm{~min}$ (figure 3 ). For HR, the corresponding values were $0.9 \pm 1.7 \mathrm{~min}$ at light intensity, $7.4 \pm 6.8 \mathrm{~min}$ at moderate intensity, $10.6 \pm 7.1 \mathrm{~min}$ at vigorous intensity and $0.9 \pm 2.0 \mathrm{~min}$ at near-maximal to maximal intensity (figure 3). Figure 4 shows a representative $\mathrm{HR}$ and $\mathrm{V}_{2}$ curve for one of the participants during exergaming. 


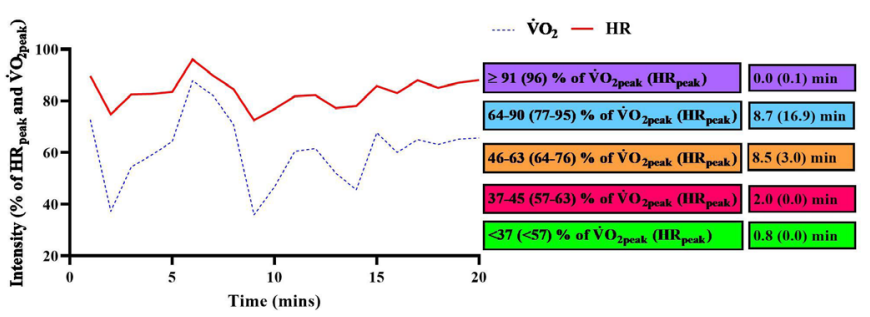

Figure 4 Example of heart rate (HR) and oxygen uptake $\left(\mathrm{VO}_{2}\right)$ curve for a representative participant during exergaming. Intensity expressed as a percentage of heart rate peak $\left(\mathrm{HR}_{\text {peak }}\right)$ and peak oxygen uptake $\left(\dot{\mathrm{V}} \mathrm{O}_{2 \text { peak }}\right)$. Intensity zones categorised into 'very light' $(<37 \%$ VंO $/<57 \%$ $\left.\mathrm{HR}_{\text {peak }}\right)$, 'light' (37\%-45\% $\left.\mathrm{VO}_{2 \text { eak }} / 57 \%-63 \% \mathrm{HR}_{\text {peak }}\right)$ ), 'moderate' (46\%-63\% نं $\left.{ }_{2 \text { peak }} / 64 \%-76 \% \mathrm{HR}_{\text {peak }}\right)$, 'vigorous' $\left(64 \%-90 \% \mathrm{VO}_{2 \text { eak }} / 77 \%-95 \% \mathrm{HR}_{\text {peak }}\right)$ and 'Near-maximal to maximal' ( $\left.\geq 91 \% \mathrm{VO}_{\text {2peak }} / \geq 96 \% \mathrm{HR}_{\text {peak }}^{\text {peak }}\right)$.

\section{$\mathrm{HR}-\mathrm{VO}_{2}$ relationship}

A linear regression established that HR could significantly predict $\dot{\mathrm{VO}}_{2}(\mathrm{p}<0.05$ for all participants $)$ and accounted for $74.1 \%$ of the variance in $\dot{\mathrm{VO}}_{2}$ (range: $0.46-0.90 \mathrm{R}^{2}$ ). When estimated from $\mathrm{HR}$, both average and peak $\mathrm{V}_{2}$ were significantly higher than measured values during exergaming (both $\mathrm{p}<0.05$ ) (figure 2). The Bland and Altman plot of measured versus estimated $\dot{\mathrm{VO}} \mathrm{O}_{2}$ revealed that although all differences were within the $95 \%$ limits of agreement for both average and peak $\dot{\mathrm{VO}}_{2}$, the mean difference was about $-9 \%$ for estimated versus measured $\dot{\mathrm{VO}}_{2}$. The Bland and Altman plot also revealed individual differences of $-15.4 \%$ and $-20.1 \%$ for peak and average, respectively (figure 5).
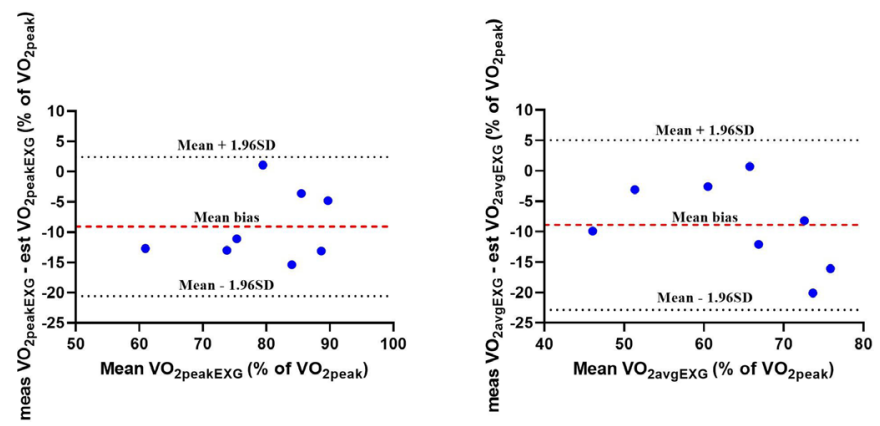

Figure 5 Bland and Altman plot of difference between measured and estimated peak (left plot) and average (right plot) oxygen uptake $\left(\mathrm{V}_{2}\right)$ during exergaming. Intensity expressed as a percentage of peak oxygen uptake $\left(\dot{\mathrm{VO}}_{2 \text { peak }}\right)$. Measured peak oxygen uptake during exergaming $\left(\right.$ measVO $\left._{2 \text { peakEXG }}\right)$, estimated peak oxygen uptake during exergaming (est $\mathrm{V}_{2 \text { peakEXG}}$ ), mean of measured and estimated peak oxygen uptake (mean $\dot{\mathrm{V}} \mathrm{O}_{2 \text { peakEXG }}$ ), measured average oxygen uptake during exergaming (meas $\dot{V}_{\text {2avgEXG}}$ ), estimated average oxygen uptake during exergaming (estV̈ $\left.{ }_{\text {2avgEXG }}\right)$ and mean of measured and estimated average oxygen uptake (mean $\dot{\mathrm{V}}_{\text {2avgEXG }}$ ).
Correlation between individuals' $\dot{\mathrm{V}} \mathrm{2peak}_{\text {and exercise }}$ intensity

There was no significant correlation between $\dot{\mathrm{VO}}_{2 \text { peak }}$ measured during the incremental exercise test and peak $(r=-0.279, \mathrm{p}=0.44)$ or average $(r=-0.275, \mathrm{p}=0.443)$ relative exercise intensity during exergaming.

\section{DISCUSSION}

The main findings of this pilot study were: (1) the average and peak $\dot{\mathrm{V}} \mathrm{O}_{2}$ during the exergaming session were with moderate and vigorous intensity, respectively, (2) both average and peak HR were classified as vigorous intensity and (3) although HR variance could significantly explain a large portion of the variation in $\dot{\mathrm{VO}}_{2}$ during the exergaming session, HR overestimated exercise intensity. Taken together, our results indicate that exergaming can be a viable exercise alternative, not only as a means to increase physical activity levels but also as an efficient strategy to improve $\dot{\mathrm{VO}}_{\text {2peak }}$

\section{Exercise intensity}

This is the first study to investigate $\dot{\mathrm{VO}}$, while playing the exergame Pedal Tanks. Our findings show that this particular exergame can elicit moderate-to-vigorous exercise intensities. This is in contrast to most previous studies on exercise intensity during exergaming, where light-tomoderate exercise intensities have been reported, ${ }^{15-17}$ which is inferior to isoenergetic vigorous intensity exercise for improving health and fitness. ${ }^{8} 9$ However, some previous studies have demonstrated moderate-tovigorous exercise intensities during exergaming. ${ }^{17} 182728$ These studies contain some methodological differences, compared with our study, that should be highlighted. Although Viana et $a l^{18}$ showed that exergaming could elicit $\dot{\mathrm{VO}}_{2}$ classified as vigorous exercise intensity, the average intensity would be categorised as low. In addition, the exergame utilised in their study was a type that simulates regular exercise, which may have a limited reach for individuals who are typically not motivated by traditional training. ${ }^{14}$ Bailey and McInnis ${ }^{28}$ assessed several exergames and found that they all elicited moderate-tovigorous intensities. However, $\dot{\mathrm{VO}}$, while exergaming was converted to metabolic equivalent task values by dividing by $3.5 \mathrm{~mL} \cdot \mathrm{kg}^{-1} \cdot \mathrm{min}^{-1}$, failing to take into account individual differences in $\dot{\mathrm{VO}}_{2 \text { peak }}$ and therefore individual differences in relative exercise intensity. ${ }^{24}$ Finally, in their assessment of intensity for several exergames, $\mathrm{Wu} e t a l^{27}$ found one exergame where the average relative intensity was very similar to that in our study (58\% vs $62 \%$ of $\left.\dot{\mathrm{V}} \mathrm{O}_{2 \text { peak }}\right)$. However, intensity was only assessed and averaged over $3 \mathrm{~min}$ versus $20 \mathrm{~min}$ in our study, which could indicate a lower intensity over longer duration. In a recent study, Farrow et $a l^{29}$ investigated the effects of virtual reality exergaming during HIIT, consisting of eight $60 \mathrm{~s}$ intervals at $>70 \%$ of maximum power output with $60 \mathrm{~s}$ recovery in-between. They found that exergaming improved the power output that participants exercised at during HIIT and found average HR to be 
around $88 \%-90 \%$ of $\mathrm{HR}_{\max }$ for the 60 s intervals. However, compared with our study where both torque and cadence are self-selected, in that study torque was selected by the researchers and participants were encouraged to work at a minimum of $70 \%$ of their maximum power output. We are not aware of any previous studies on exergaming that have investigated time spent in different intensity zones. Our novel findings, where almost half of the exergaming session was spent at or above vigorous exercise intensity, are comparable to exercise intensity during recreational 5 -a-side soccer. ${ }^{30}$ The measured intensity for exergame in this study is well within the The American College of Sports Medicine's (ACSM) recommendations for developing cardiorespiratory fitness. ${ }^{24}$ Based on our initial results, playing this cycling exergame three times per week for 40 min per session should be more than sufficient to accumulate ACSM's recommended levels of activity.

\section{Correlation between $\mathrm{V}_{2 \text { peak }}$ and exercise intensity}

We hypothesised that those with highest $\mathrm{VO}_{2 \text { peak }}$ would achieve the lowest relative exercise intensities. However, our findings show no significant negative correlation between $\dot{\mathrm{V}} \mathrm{O}_{\text {2peak }}$ and exercise intensity in this study. This finding indicate that irrespective of aerobic fitness, the exergame enables participants with a $\dot{\mathrm{V}} \mathrm{O}_{2 \text { peak }}$ lower or the same as the normal population $(27.4-55.1 \mathrm{~mL} \cdot \mathrm{k}$ $\left.\mathrm{g}^{-1} \cdot \mathrm{min}^{-1}\right),{ }^{31}$ to exercise at an intensity that can improve cardiorespiratory fitness. These findings are in line with an earlier study in recreational 5-a-side soccer where there was no correlation between $\mathrm{V}_{2 \text { peak }}$ and relative exercise intensity. ${ }^{30}$ In contrast, two studies in small-play football and 4-a-side handball reported a ceiling effect, where the players with the highest $\mathrm{V}_{2}$ peak attained the lowest relative exercise intensities. ${ }^{32} 33^{2 \text { peak }}$ One reason for the differences between these studies could be that our participants had lower average $\dot{\mathrm{V}} \mathrm{O}_{2 \text { peak }}$ levels $(40.9 \mathrm{~mL} \cdot \mathrm{k}-$ $\left.\mathrm{g}^{-1} \cdot \mathrm{min}^{-1}\right)$ compared with those in the studies by Hoff $e t$ $a l^{33}$ and Buchheit et $a l^{32}\left(67.8\right.$ and $57.3 \mathrm{~mL} \cdot \mathrm{kg}^{-1} \cdot \mathrm{min}^{-1}$, respectively). Another possible explanation for the lack of significant correlation between $\dot{\mathrm{VO}}_{2 \text { peak }}$ and attained exercise intensity during exergaming in this study is the low sample size and relatively heterogeneous fitness level among the participants. In future studies of exercise intensity during exergaming, individuals with higher aerobic capacities than the normal population should be included, although the critical target group for exergaming is those not already involved in traditional endurance training. ${ }^{14}$

\section{$\mathrm{HR}-\mathrm{VO}_{2}$ relationship}

Although previous studies have suggested that there is a discrepancy between $\mathrm{HR}$ and $\dot{\mathrm{VO}}_{2}(17,18)$ during exergaming, this is the first study to actually assess the association between $\mathrm{HR}$ and $\mathrm{V}_{2}$. Our findings that $\mathrm{HR}$ variance could explain $\sim 75 \%$ of the variation in $\dot{\mathrm{V}} \mathrm{O}_{2 \text { peak }}$ are similar to reports on other forms of intermittent exercise. ${ }^{30}$ Furthermore, our results show large individual variation in how much of the $\mathrm{HR}$ variance can explain the variation in $\dot{\mathrm{V}}_{2}$. In addition, comparisons between estimated and measured $\dot{\mathrm{V}}_{2}$ show that $\mathrm{HR}$ overestimate $\dot{\mathrm{V}} \mathrm{O}_{2}$ when playing the exergame Pedal Tanks, which most likely is due to the intermittent nature of the game. ${ }^{2133}$ Our results suggest that HR measurements are sufficient to monitor exercise intensity during exergaming on a group level, although it should be complemented with $\mathrm{V}_{2}$ to fully capture individual differences and not overestimate aerobic involvement.

\section{Limitations}

This study is not without limitations. With only 10 participants, inter-individual differences may have affected our findings. Such a low sample size may have compromised our study's power to detect the full range of intensity the cycling exergame can elicit. Using a cycling test to measure $\mathrm{VO}_{2 \text { peak }}$ could be considered as a limitation to our study, as cycling tests tend to produce lower values than tests performed on a treadmill. ${ }^{34}$ This means that the relative exercise intensity could be overestimated in our study. We only measured each participants' $\dot{\mathrm{V}} \mathrm{O}_{2}$ during a single exergaming session and cannot rule out that the intensity during exergaming can change over time. However, we have previously shown that HR is not changed over three sessions playing this cycling exergame. ${ }^{20}$ We only assessed acute responses and future studies should assess the long-term effectiveness of exergaming to improve $\mathrm{V}_{2 \text { peak }}$. Although average and peak intensity were moderate and vigorous, respectively, some individuals did not reach those exercise intensities. We therefore suggest that game developers involve heart-rate power-ups, which will reward players during the game whenever they reach a certain specified heart rate target zone. ${ }^{35}$ We believe this will further ensure high exercise intensities while playing, without compromising enjoyment.

\section{CONCLUSIONS}

The cycling exergame we tested elicits vigorous intensities for both $\mathrm{HR}$ and $\mathrm{V}_{2}$, irrespective of the individuals' aerobic capacity. Exergaming may therefore be a feasible alternative to traditional endurance training. Furthermore, our findings demonstrate that using HR to assess exercise intensity during exergaming is valid but that aerobic involvement may be overestimated. Larger studies on diverse samples of adults are required to confirm and expand on our results.

\section{Twitter Trine Moholdt @trinemoholdt}

Acknowledgements The testing was undertaken at the NeXt Move Core Facility, Norwegian University of Science and Technology (NTNU). NeXt Move is funded by the Faculty of Medicine and Health at NTNU and Central Norway Regional Health Authority.

Contributors JB and TM was involved in the study design and analysed the data. $\mathrm{JB}$ collected the data. Both authors interpreted the results, contributed to the drafting and revised the manuscript.

Funding The study was funded by the Liaison Committee between the Central Norway Regional Health Authority (RHA), grant number 17/38297, and The Norwegian Fund for Post-Graduate Training in Physiotherapy, grant number 97832. 
Competing interests None declared.

Patient consent for publication Not required.

Ethics approval The Norwegian Centre for Research data has approved the study protocol (reference number 53557).

Provenance and peer review Not commissioned; externally peer reviewed.

Data availability statement Data are available upon reasonable request. All data from the study are available on request.

Open access This is an open access article distributed in accordance with the Creative Commons Attribution Non Commercial (CC BY-NC 4.0) license, which permits others to distribute, remix, adapt, build upon this work non-commercially, and license their derivative works on different terms, provided the original work is properly cited, appropriate credit is given, any changes made indicated, and the use is non-commercial. See: http://creativecommons.org/licenses/by-nc/4.0/.

ORCID iDs

Jonathan Berg http://orcid.org/0000-0002-5291-6227

Trine Moholdt http://orcid.org/0000-0003-1024-8088

\section{REFERENCES}

1 Ekelund U, Steene-Johannessen J, Brown WJ, et al. Does physical activity attenuate, or even eliminate, the detrimental association of sitting time with mortality? A harmonised meta-analysis of data from more than 1 million men and women. The Lancet 2016;388:1302-10.

2 Schmid D, Ricci C, Baumeister SE, et al. Replacing sedentary time with physical activity in relation to mortality. Med Sci Sports Exerc 2016;48:1312-9.

3 Lee D-C, Sui X, Ortega FB, et al. Comparisons of leisure-time physical activity and cardiorespiratory fitness as predictors of all-cause mortality in men and women. $\mathrm{Br} J$ Sports Med 2011;45:504-10.

4 WHO. Global recommendations for physical activity and health Geneva, Switzerland: World Health Organization, 2010.

5 Hansen $\mathrm{BH}$, Anderssen SA, Steene-Johannessen J, et al. Fysisk aktivitet og sedat tid blant voksne og eldre i Norge - nasjonal kartlegging 2014-2015. In: Helsedirektoratet, editor. Oslo: Norway, 2015.

6 Salmon J, Owen N, Crawford D, et al. Physical activity and sedentary behavior: a population-based study of barriers, enjoyment, and preference. Health Psychol 2003;22:178-88.

7 Trost SG, Owen N, Bauman AE, et al. Correlates of adults participation in physical activity: review and update. Med Sci Sports Exerc 2002;34:1996-2001.

8 Swain DP, Franklin BA. Comparison of cardioprotective benefits of vigorous versus moderate intensity aerobic exercise. Am J Cardiol 2006;97:141-7.

9 Helgerud J, Høydal K, Wang E, et al. Aerobic high-intensity intervals improve VO2max more than moderate training. Med Sci Sports Exerc 2007;39:491-8

10 Oh Y, Yang S. Defining exergames \& exergaming. Proceedings of Meaningful Play 2010:1-17.

11 Graves LEF, Ridgers ND, Williams K, et al. The physiological cost and enjoyment of Wii fit in adolescents, young adults, and older adults. J Phys Act Health 2010;7:393-401.

12 Schiro EC. Norsk mediebarometer 2018. Oslo-Kongsvinger, 2018.

13 O'Loughlin EK, Dugas EN, Sabiston CM, et al. Prevalence and correlates of exergaming in youth. Pediatrics 2012;130:806-14.

14 Hagen K, Chorianopoulos K, Wang Al, et al. Gameplay as exercise. Proceedings of the 2016 chi conference extended Abstracts on human factors in computing systems. ACM, 2016: 1872-8.
15 Graf DL, Pratt LV, Hester CN, et al. Playing active video games increases energy expenditure in children. Pediatrics 2009;124:534-40.

16 Naugle KE, Carey C, Ohlman T, et al. Improving active gaming's energy expenditure in healthy adults using structured playing Instructions for the Nintendo Wii and XBOX Kinect. $J$ Strength Cond Res 2019;33:549-58.

17 Unnithan VB, Houser W, Fernhall B. Evaluation of the energy cost of playing a dance simulation video game in overweight and non-overweight children and adolescents. Int J Sports Med 2006;27:804-9.

18 Viana RB, Vancini RL, Vieira CA, et al. Profiling exercise intensity

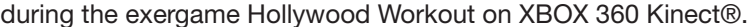
PeerJ 2018;6:e5574

19 McBain T, Weston M, Crawshaw P, et al. Development of an Exergame to deliver a sustained dose of high-intensity training: formative pilot randomized trial. JMIR Serious Games 2018;6:e4.

20 Moholdt T, Weie S, Chorianopoulos K, et al. Exergaming can be an innovative way of enjoyable high-intensity interval training. BMJ Open Sport Exerc Med 2017;3:e000258.

21 Hagen K, Weie S, Chorianopoulos K, et al. Pedal Tanks. In: Chorianopoulos K, Divitini M, Baalsrud Hauge J, et al, eds. Entertainment Computing - ICEC 2015. Trondheim, Norway, 2015.

22 Edvardsen E, Hem E, Anderssen SA. End criteria for reaching maximal oxygen uptake must be strict and adjusted to sex and age: a cross-sectional study. PLoS One 2014;9:e85276.

23 Nes BM, Janszky I, Wisløff U, et al. Age-predicted maximal heart rate in healthy subjects: the HUNT fitness study. Scand J Med Sci Sports 2013;23:697-704.

24 Garber CE, Blissmer B, Deschenes MR, et al. American College of sports medicine position stand. quantity and quality of exercise for developing and maintaining cardiorespiratory, musculoskeletal, and neuromotor fitness in apparently healthy adults: guidance for prescribing exercise. Med Sci Sports Exerc 2011;43:1334-59.

25 Londeree BR, Ames SA. Trend analysis of the \% VO2 max-HR regression. Med Sci Sports 1976;8:123-5.

26 Bland JM, Altman DG. Statistical methods for assessing agreement between two methods of clinical measurement. Lancet 1986;1:307-10.

27 Wu P-T, Wu W-L, Chu I-H. Energy expenditure and intensity in healthy young adults during exergaming. Am J Health Behav 2015;39:557-61

28 Bailey BW, Mclnnis K. Energy cost of exergaming: a comparison of the energy cost of 6 forms of exergaming. Arch Pediatr Adolesc Med 2011;165:597-602.

29 Farrow M, Lutteroth C, Rouse PC, et al. Virtual-reality exergaming improves performance during high-intensity interval training. Eur $J$ Sport Sci 2019;19:719-27.

30 Castagna C, Belardinelli R, Impellizzeri FM, et al. Cardiovascular responses during recreational 5-a-side indoor-soccer. J Sci Med Sport 2007;10:89-95.

31 Edvardsen E, Hansen $\mathrm{BH}$, Holme IM, et al. Reference values for cardiorespiratory response and fitness on the treadmill in a 20- to 85-year-old population. Chest 2013;144:241-8.

32 Buchheit M, Lepretre PM, Behaegel AL, et al. Cardiorespiratory responses during running and sport-specific exercises in handball players. J Sci Med Sport 2009;12:399-405.

33 Hoff J, Wisløff U, Engen LC, et al. Soccer specific aerobic endurance training. Br J Sports Med 2002;36:218-21.

34 Beltz NM, Gibson AL, Janot JM, et al. Graded Exercise Testing Protocols for the Determination of VO max: Historical Perspectives, Progress, and Future Considerations. J Sports Med 2016;2016:1-12.

35 Ketcheson M, Ye Z, Graham TCN. Designing for exertion: how heartrate power-ups increase physical activity in exergames. London, United Kingdom: Proceedings of the 2015 Annual Symposium on Computer-Human Interaction in Play, 2015 